\title{
Quantifying uncertainty in climatological fields from GPS radio occultation: an empirical-analytical error model
}

\author{
B. Scherllin-Pirscher ${ }^{1,2,3}$, G. Kirchengast ${ }^{3}$, A. K. Steiner ${ }^{3}$, Y.-H. Kuo ${ }^{2}$, and U. Foelsche ${ }^{3}$ \\ ${ }^{1}$ Advanced Study Program, National Center for Atmospheric Research (NCAR), Boulder, Colorado, USA \\ ${ }^{2}$ COSMIC Project Office, University Corporation for Atmospheric Research (UCAR), Boulder, Colorado, USA \\ ${ }^{3}$ Wegener Center for Climate and Global Change (WEGC) and Institute for Geophysics, Astrophysics, \\ and Meteorology/Institute of Physics (IGAM/IP), University of Graz, Graz, Austria
}

Received: 7 March 2011 - Published in Atmos. Meas. Tech. Discuss.: 11 May 2011

Revised: 14 September 2011 - Accepted: 18 September 2011 - Published: 29 September 2011

\begin{abstract}
Due to the measurement principle of the radio occultation (RO) technique, $\mathrm{RO}$ data are highly suitable for climate studies. RO profiles can be used to build climatological fields of different atmospheric parameters like bending angle, refractivity, density, pressure, geopotential height, and temperature. RO climatologies are affected by random (statistical) errors, sampling errors, and systematic errors, yielding a total climatological error. Based on empirical error estimates, we provide a simple analytical error model for these error components, which accounts for vertical, latitudinal, and seasonal variations. The vertical structure of each error component is modeled constant around the tropopause region. Above this region the error increases exponentially, below the increase follows an inverse height power-law. The statistical error strongly depends on the number of measurements. It is found to be the smallest error component for monthly mean $10^{\circ}$ zonal mean climatologies with more than 600 measurements per bin. Due to smallest atmospheric variability, the sampling error is found to be smallest at low latitudes equatorwards of $40^{\circ}$. Beyond $40^{\circ}$, this error increases roughly linearly, with a stronger increase in hemispheric winter than in hemispheric summer. The sampling error model accounts for this hemispheric asymmetry. However, we recommend to subtract the sampling error when using RO climatologies for climate research since the residual sampling error remaining after such subtraction is estimated to be only about $30 \%$ of the original one or less. The systematic error accounts for potential residual biases in the measurements as well as in the retrieval process and generally dominates the total climatological error. Overall the total error in monthly means is estimated to be smaller than $0.07 \%$ in refractivity
\end{abstract}

Correspondence to:

B. Scherllin-Pirscher

(pirscher@ucar.edu) and $0.15 \mathrm{~K}$ in temperature at low to mid latitudes, increasing towards higher latitudes. This study focuses on dry atmospheric parameters as retrieved from RO measurements so for context we also quantitatively explain the difference between dry and physical atmospheric parameters, which can be significant at altitudes below about $6 \mathrm{~km}$ (high latitudes) to $10 \mathrm{~km}$ (low latitudes).

\section{Introduction}

Global climate monitoring and trend detection require accurate and long-term consistent data records. Such data are needed in the upper troposphere/lower stratosphere (UTLS) region since most conventional upper air measurements are based on radiometric physical devices, which often deteriorate with time. Those instruments were designed for weather observation and not for climate monitoring, and the data need sophisticated correction and inter-calibration for the construction of a climate record (e.g., Christy and Spencer, 2005; Haimberger et al., 2008).

The radio occultation (RO) proof of concept mission GPS/Met, launched in 1995, showed that RO measurements promise to overcome these shortcomings and data are well suited for atmospheric studies (Kursinski et al., 1996; Rocken et al., 1997; Steiner et al., 1999). Due to its measurement principle, RO data are long-term stable, of high accuracy, and available under virtually all weather conditions. Furthermore, RO data exhibit a high vertical resolution, are available globally, and feature best quality in the UTLS region (e.g., Kursinski et al., 1997).

GPS/Met provided data intermittently within the years 1995 to 1997 (Rocken et al., 1997). Data from SAC-C and CHAMP (both launched in 2000), GRACE (launch

Published by Copernicus Publications on behalf of the European Geosciences Union. 
2002), Formosat-3/COSMIC (F3C) (6 satellites, launch 2006), MetOp-A (launch 2006), TerraSAR-X (launch 2007), C/NOFS (launch 2008), OCEANSAT-2 (launch 2009), and TanDEM-X (launch 2010) complete the RO record currently available (not all data are available in real time for operations) and allow an investigation of the quality and error characteristics of RO climate products on a multi-year basis.

The RO method (Melbourne et al., 1994; Kursinski et al., 1997; Hajj et al., 2002) is an active satellite-to-satellite limb sounding technique. It utilizes artificial signals continuously transmitted by Global Positioning System (GPS) satellites. Due to vertical density gradients in the atmosphere, the signals are refracted until they are received on a low Earth orbit (LEO) satellite. The prime measurement quantity on the LEO satellite is the excess phase of the GPS signal. Due to the relative motion of the GPS and the LEO satellites, the GPS signals penetrate the atmosphere at different tangent heights, which results in a near vertical profile of excess phase measurements. Since RO measurements are based on time delays, they are traceable to the international time standard (definition of the second), i.e., an absolute SI-based unit (Leroy et al., 2006). This results in the benefit that measurements do not have to be additionally calibrated, have negligible drift with time, and do not exhibit instrument-toinstrument biases. We note that even though the measurements exhibit these beneficial characteristics, the data processing can induce a bias.

The characteristics and quality of RO data allow the calculation of monthly, seasonal, and annual mean climatological fields (Foelsche et al., 2008, 2009b), which can be used for climate studies (Steiner et al., 2009; Schmidt et al., 2010). The number of high quality measurements provided by a single satellite within one month (usually larger than 3500) is sufficient to calculate monthly climatologies of atmospheric parameters with a horizontal resolution of $10^{\circ}$ zonal bands. If data from multi-satellites are used, the temporal and/or horizontal resolution can even be higher. The quality of RO climatologies depends on the number of RO profiles as well as their sampling times and locations (sampling error), residual bias errors of the measurements and/or the retrieval process (systematic error), and random errors (statistical error). Several studies indicate that the systematic error is small (e.g., Gobiet et al., 2007) and also long-term stability is given (Ho et al., 2009). While the magnitude of the statistical error primarily depends on the number of measurements, the sampling error is also strongly affected by atmospheric variability (Pirscher et al., 2007; Foelsche et al., 2008). Largest sampling errors occur at high latitudes during wintertime, where atmospheric variability is strongest. Foelsche et al. (2011a) showed that monthly mean CHAMP, GRACE-A, and F3C global-average climatologies agree to within $<0.05 \%$ in refractivity and $<0.05 \mathrm{~K}$ in dry temperature for almost every satellite and month, provided that the sampling error is subtracted as we suggest as a general recommendation also in this paper.
This study aims at investigating and quantifying error characteristics of climatological fields from RO data. Including the statistical error, sampling error, and potential systematic error contributions, we provide an estimate of the total climatological error for RO based climatologies. Section 2 gives a description of the RO data set and the European Centre for Medium-Range Weather Forecasts (ECMWF) data set used (the latter used, e.g., to estimate the sampling error). In Sect. 3 we generically introduce the analytical error model for the climatological error and its components. In Sect. 4 we separate the RO climatological error into its components and provide a simple modeling of them based on the analytical model formulation. For context, we quantitatively explain the differences between dry and physical atmospheric parameters in Sect. 5. Conclusions are drawn in Sect. 6.

\section{Data}

\subsection{RO data}

We analyze monthly mean climatologies of different atmospheric parameters delivered by RO measurements: bending angle $\alpha$ as a function of impact altitude, refractivity $N$, dry density $\varrho_{\text {dry }}$, dry pressure $p_{\text {dry }}$, and dry temperature $T_{\text {dry }}$ as a function of mean sea level (m.s.l.) altitude, and geopotential height as a function of dry pressure altitude ("dry geopotential height" $Z_{\mathrm{dry}}$ ). Error estimates of parameters with exponential altitude dependence (bending angle, refractivity, dry density, and dry pressure) are given in percent, while errors of dry geopotential height and dry temperature are given in absolute units (meter and Kelvin, respectively). Temperature errors may be readily scaled to relative errors as well, by multiplying them by $0.4 \% \mathrm{~K}^{-1}$ (from the reasonable approximation that $100 \%$ is $250 \mathrm{~K}$ ).

We use data from CHAMP, GRACE-A, and F3C and focus on the time period from January 2007 to December 2009. CHAMP, which was in orbit from 2000 to 2010 delivered data only until October 2008, GRACE-A data are continuously available since March 2007, and F3C data are available for the whole time period. The error analysis is based on RO data processed at WEGC (Wegener Center for Climate and Global Change). We use WEGC OPSv5.4 data (Steiner et al., 2009; Pirscher, 2010) for this study but we note that error estimations are, in general, applicable to RO data delivered by other processing centers as well. Data are investigated for different latitude regions in the altitude range between $4 \mathrm{~km}$ and $35 \mathrm{~km}$ (UTLS region).

Figure 1 shows the latitudinal distribution of the monthly number of F3C (top), CHAMP, and GRACE-A (bottom) measurements. Since F3C satellites are able to perform setting and rising occultation measurements, the number of profiles is significantly larger than that of CHAMP and GRACE-A, which can only perform setting RO measurements. The mean number of profiles per $10^{\circ}$ latitudinal 

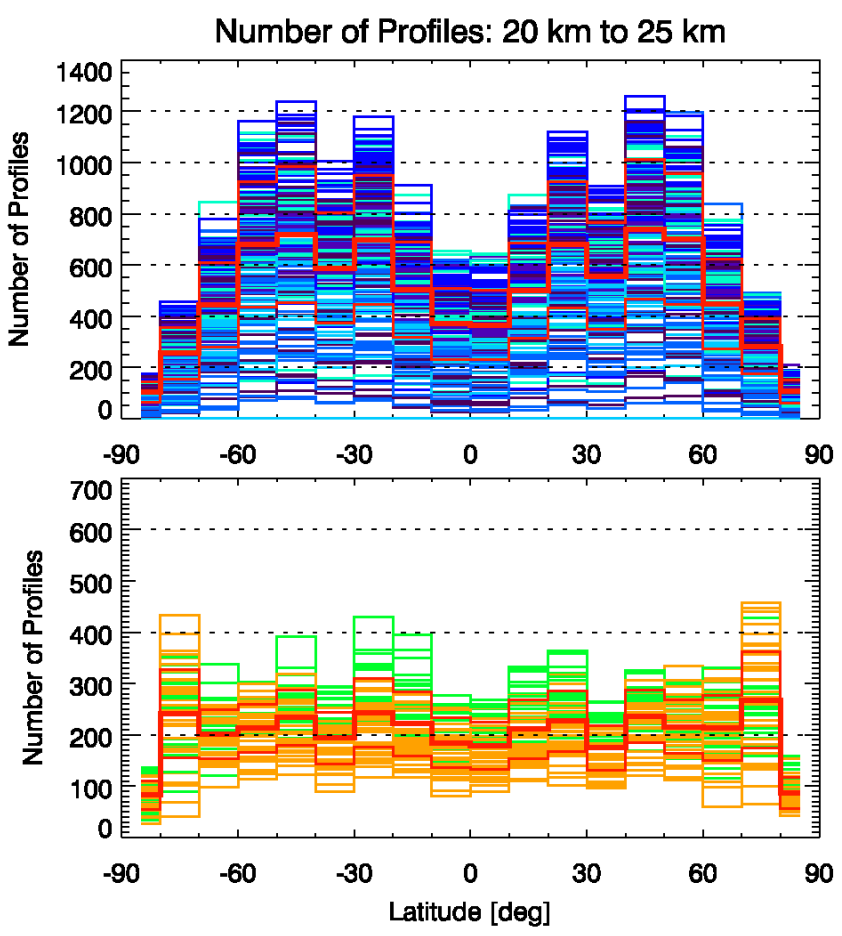

Fig. 1. Number of F3C (top) and CHAMP/GRACE-A (bottom) measurements as a function of latitude for each month (light lines) from 2007 to 2009 (note the different y-axis scale). Data from individual F3C satellites are depicted in different blue lines, CHAMP is shown in green, GRACE-A in yellow; the mean number of profiles per latitude bin and the related standard deviation are shown as heavy, respectively light red lines.

band amounts approximately to 600 for F3C and to 200 for CHAMP and GRACE-A. Due to different orbit parameters of F3C, CHAMP, and GRACE-A, the respective latitudinal distributions of RO events show some distinctive different characteristics. While CHAMP and GRACE-A fly in an orbit with high inclination $\left(87.2^{\circ}\right.$ and $89.0^{\circ}$, respectively), the $\mathrm{F} 3 \mathrm{C}$ satellites are in orbits with only $72.0^{\circ}$ inclination. The smaller inclination limits the number of $\mathrm{RO}$ events beyond $70^{\circ}$ latitude. While the number of F3C measurements significantly decreases beyond about this latitude already, it remains stable up to $80^{\circ}$ latitude for CHAMP and GRACE-A. We note that the latitudinal distribution of the RO event density (occultations per area) looks different than the total number of events with more occultations at high latitudes than at low latitudes (e.g., Pirscher, 2010).

RO climatologies are obtained from "binning" and "averaging" of RO profiles (Foelsche et al., 2008). We use OPSv5.4/CLIPSv1.3 climatology data products of WEGC. To derive these RO climatologies from individual measurements, profiles are first interpolated to a common $200 \mathrm{~m}$ altitude grid. Next they are gathered into "fundamental bins" with a horizontal resolution of $5^{\circ}$ latitude and $60^{\circ}$ longitude and averaged (including weighting by cosine of latitude, not significant for $5^{\circ}$ latitude bins, though). These "fundamental climatologies" are then aggregated to larger horizontal bins by weighting with the number of profiles (longitudinal aggregation) and the bin area (latitudinal aggregation) (Foelsche et al., 2009b; Pirscher, 2010). $10^{\circ}$ zonal bands are the basic horizontal resolution of single-satellite monthly mean RO climatologies. WEGC RO climatologies are available at www.wegcenter.at/globclim.

\subsection{ECMWF data}

We utilize ECMWF operational analysis fields to estimate the sampling error of RO climatologies. ECMWF provides four global analysis fields every day. They represent the atmospheric state at 00:00 UTC, 06:00 UTC, 12:00 UTC, and 18:00 UTC. The horizontal resolution of ECMWF fields we use (triangular truncation T42) is chosen to match the horizontal resolution of the RO profiles $(\approx 300 \mathrm{~km}$; e.g., Kursinski et al., 1997). On the one hand we extract co-located profiles from these global analysis fields and on the other hand we derive a complete 3-D ECMWF field for each month.

Co-located reference profiles are extracted for each single RO event and for each atmospheric parameter retrieved from RO measurements. Co-located profiles are extracted from that ECMWF field, of which the time layer is closest to the mean RO event time. Co-location is derived from spatial interpolation to the mean geographic event location. The "full" 3-D ECMWF reference field is derived on evenly distributed grid points with a horizontal resolution of $2.5^{\circ} \times 2.5^{\circ}$. It is calculated from averaging over all analysis fields available within one month (i.e., data of all days and all time layers of the month). Currently (OPSv5.4) WEGC provides full ECMWF reference fields only for refractivity, dry pressure, and dry temperature, but not for bending angle and dry geopotential height.

\section{Error model}

The error components contributing to the total climatological error $s_{\text {totErr }}$ are the statistical error $s_{\text {statErr }}$, the residual sampling error $s_{\text {resSamplErr, }}$ and the systematic error $s_{\text {sysErr }}$, combined with the reasonable assumption that they are uncorrelated:

$s_{\text {totErr }}=\sqrt{s_{\text {statErr }}^{2}+s_{\text {resSamplErr }}^{2}+s_{\text {sysErr }}^{2}}$.

If the sampling error would not be subtracted from a climatology, the total error would contain the full sampling error $s_{\text {samplErr }}$ instead of only the residual one. We introduce an empirical-analytical error model, which can be used to model all components of the total climatological error separately after which they are then RMS-combined according to Eq. (1). Alternatively full climatological error fields, such as supplied as part of WEGC climatology products, can be used (see Sect. 4). 
The model we introduce is an extension and generalization of the error model provided by Steiner and Kirchengast (2005) and Steiner et al. (2006) as well as Scherllin-Pirscher et al. (2011). Steiner and Kirchengast (2005) and Steiner et al. (2006) established a vertical model for the GPS RO observational error (i.e., the estimated statistical error of individual $\mathrm{RO}$ profiles relative to corresponding "true" profiles at mean tangent point location). As used by Scherllin-Pirscher et al. (2011) their model $s_{\text {model }}$ as a function of altitude $z$ is adopted here as well and formulated as

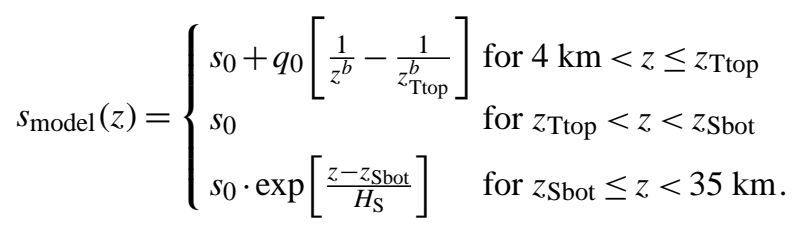

It utilizes the parameters $s_{0}$, which is the error in the UTLS core region, $z_{\text {Ttop }}$ and $z_{\text {Sbot }}$, which are the top level of the troposphere domain and the bottom level of the stratosphere domain, respectively, $q_{0}$ the best fit parameter for the tropospheric model, $b$ its exponent, and $H_{\mathrm{S}}$ the stratospheric error scale height. The model distinguishes between three different altitude regions: a region around/near the tropopause, where the error is constant and smallest, a region above, where the error increases exponentially, and a region below, where the error follows an inverse height power-law.

Scherllin-Pirscher et al. (2011) extended this vertical error model and allocated a latitudinal and seasonal dependence to the error scale height parameter $H_{\mathrm{S}}$. Extending this further, for enabling application to any error component modeled here, we now formulate a general description of latitudinal and seasonal variations in the form

$x(\varphi, \tau)=x_{0}+\Delta x f(\varphi)\left[f_{\Delta x 0}+f_{\Delta x \mathrm{~s}} g(\tau, \varphi)\right]$,

where $x_{0}$ is the basic mean magnitude of the parameter $x, \Delta x$ is the maximum amplitude of latitudinal and/or seasonal variations, $f(\varphi)$ accounts for latitudinal dependence, and $g(\tau, \varphi)$ for seasonal variations. The factors $f_{\Delta x 0}$ and $f_{\Delta x \mathrm{~s}}$, which can adopt values between zero and unity, assign the fraction of $\Delta x$ that shall flow into latitudinal change and seasonality, respectively. All these constants and functions on the right hand side of Eq. (3) are prescribed in a way to provide a suitable latitudinally and seasonally dependent model of the parameter $x$ (see Sect. 4 for practical use in the empirical error model formulations).

In the same way as used by Scherllin-Pirscher et al. (2011), the functions $f(\varphi)$ and $g(\tau, \varphi)$ are modeled according to

$$
f(\varphi)=\max \left\{0, \min \left[\left(\frac{|\varphi|-\varphi_{\Delta x \mathrm{lo}}}{\varphi_{\Delta x \mathrm{hi}}-\varphi_{\Delta x \mathrm{lo}}}\right), 1\right]\right\}
$$

and

$g(\tau, \varphi)=\operatorname{sign}(\varphi) \cos (2 \pi \tau)$, with

$$
\tau= \begin{cases}\frac{(m-1)-m_{\text {lag }}}{12} & \text { for } m \in\{1, \ldots, 12\} \\ \frac{3 s-m_{\text {lag }}}{12} & \text { for } s \in\{1, \ldots, 4\} \\ \frac{(d-15)-30.5 m_{\text {lag }}}{366} & \text { for } d \in\{1, \ldots, 366\} .\end{cases}
$$

The function $f(\varphi)$ is zero at low latitudes (equatorwards of $\left.\varphi_{\Delta x \mathrm{lo}}\right)$. Between $\varphi_{\Delta x \mathrm{lo}}$ and $\varphi_{\Delta x \mathrm{hi}}$ it linearly increases to +1 , polewards of $\varphi_{\Delta x \text { hi }}$ it remains constant $(+1)$. The function $g(\tau, \varphi)$ yields always positive values in the winter hemisphere and negative values in the summer hemisphere. The model can be applied on a daily base with $d$ being days of year, monthly base with $m=1$ representing January and $m=12$ being December, or seasonal base starting with $s=1$ in March-April-May (MAM).

The modeling used by Scherllin-Pirscher et al. (2011) is a special case of the general model Eq. (3), with $f_{\Delta x 0}=0$ and $f_{\Delta x \mathrm{~s}}=1$ (i.e., seasonality-only modeling of the parameter $H_{\mathrm{S}}$ in that case). Below we use the vertical error model given in Eq. (2) and apply Eq. (3) to model latitudinal and seasonal variations of $s_{0}$ as part of the modeling of the (residual) sampling error and the systematic error.

\section{GPS RO climatological error components}

In the following we discuss the statistical error, the sampling error and residual sampling error, as well as the systematic error, and provide a simple model for each of these components.

\subsection{Statistical error estimation}

Statistical errors $s_{\text {statErr }}$ are random errors and will thus be gradually diminished by averaging over many profiles. Knowledge of the observational error of individual RO profiles $s_{\text {obs }}$ or the utilization of the observational error model $s_{\text {obsModel }}$ as provided by Scherllin-Pirscher et al. (2011) together with knowledge of the number of profiles $n_{\text {prof }}$ (in any statistical bin at any altitude level) allow to estimate statistical errors in climatologies simply as

$s_{\mathrm{statErr}}=\frac{s_{\text {obs }}}{\sqrt{n_{\text {prof }}}} \approx \frac{s_{\text {obsModel }}}{\sqrt{n_{\text {prof }}}}$.

In monthly mean $10^{\circ}$ zonal mean CHAMP or GRACE-A climatologies, the number of profiles is approximately 200 per bin (see Fig. 1, bottom), which yields an error reduction of the observational error by a factor of about 14 almost everywhere on the globe (except for polar cap regions, where the number of measurements is smaller). The average number of monthly $\mathrm{F} 3 \mathrm{C}$ profiles per $10^{\circ}$ bin is approximately 600 for each single satellite (see Fig. 1, top) and gathering profiles from all six F3C satellites yields about 3600 profiles per bin, which yields an error reduction by factors of about 24 and 60, respectively. Using the WEGC OPSv5.4/CLIPSv1.3 
climatology data products, these also include $n_{\text {prof }}$ fields so

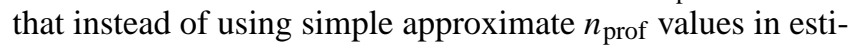
mating $s_{\text {statErr }}$ also the actual values can be used in each bin and at each altitude level.

Considering a UTLS observational error of $0.8 \%$ in bending angle, $0.35 \%$ in refractivity, $0.15 \%$ in dry pressure, $10 \mathrm{~m}$ in dry geopotential height, and $0.7 \mathrm{~K}$ in dry temperature according to Scherllin-Pirscher et al. (2011), the statistical error $s_{\text {statErr }}$ for CHAMP-type satellites/the whole F3C constellation amounts approximately to $0.06 \% / 0.015 \%$ in bending angle, $0.025 \% / 0.006 \%$ in refractivity, $0.01 \% / 0.0025 \%$ in dry pressure, $0.7 \mathrm{~m} / 0.17 \mathrm{~m}$ in dry geopotential height, and $0.05 \mathrm{~K} / 0.012 \mathrm{~K}$ in dry temperature. Averaging over larger latitudinal regions or longer temporal scales reduces the statistical error even further, by further increasing $n_{\text {prof }}$ (Eq. 7). $s_{\text {statErr }}$ is therefore, in general, the smallest contribution to the total climatological error (Eq. 1).

\subsection{Sampling error and residual sampling error estimation}

\subsubsection{Sampling error and sampling error model}

Due to discrete sampling times and locations of RO measurements, RO climatologies are affected by a sampling error. Using a reference atmosphere with adequately realistic atmospheric variability, this sampling error can be estimated, when times and locations of RO events are known. It is computed in forming the difference between the mean of all colocated reference profiles of a bin, $\bar{x}_{\text {coloc }}$, and the mean of all reference profiles at all grid points over the full averaging period available within one bin, $\bar{x}_{\text {full }}$ (Foelsche et al., 2003, 2008; Pirscher et al., 2007; Ho et al., 2009). Thus, for example, the sampling error $s_{\text {samplErr }}$ for a zonal mean monthly mean field $\left(z_{i}, \varphi_{j}, t_{k}\right)$ is calculated from

$s_{\text {samplErr }}\left(z_{i}, \varphi_{j}, t_{k}\right)=\bar{x}_{\text {coloc }}\left(z_{i}, \varphi_{j}, t_{k}\right)-\bar{x}_{\text {full }}\left(z_{i}, \varphi_{j}, t_{k}\right)$,

with $z_{i}$ being altitude levels (e.g., every $\left.200 \mathrm{~m}\right), \varphi_{j}$ latitudinal bins (e.g., every $10^{\circ}$ ), and $t_{k}$ temporal periods (e.g., every month). Note that this sampling error estimation is based on reference data only and key requirement for data to qualify as reference atmosphere is that they must reflect true spatial and temporal atmospheric variability. These criteria are, for example, fulfilled by ECMWF or National Centers for Environmental Prediction (NCEP) analysis or reanalysis fields. As introduced in Sect. 2.2 we use ECMWF analysis fields for sampling error estimation, which have proven to be very adequate for the purpose (e.g., Foelsche et al., 2008, 2011a).

Since full ECMWF reference fields are currently (OPSv5.4/CLIPSv1.3) not available at WEGC for bending angle and geopotential height, sampling error estimates for these parameters are derived from well known dependencies on other atmospheric parameters available: bending angle sampling errors are calculated from refractivity fields, geopotential height sampling errors are derived from pressure sampling errors.

As stated by Lackner (2010) (see also Ringer and Healy, 2008), refractivity gradients reflect the mean bending angle for a layer. A theoretical and empirical check showed that the factor converting refractivity gradients to bending angles is approximately $-0.5 \mathrm{mrad} /(\mathrm{N}-$ Units $/ \mathrm{km})$ in the lower stratosphere, with the factor's magnitude gradually increasing into the troposphere along with the increasing curvature of rays. Since we focus on relative bending angle errors (in units \%), the factor basically cancels, however, so its actual value can be disregarded.

Co-located ECMWF bending angle profiles and the full ECMWF bending angle field are derived from corresponding refractivity gradient fields of atmospheric layers with $5 \mathrm{~km}$ width. Subsequently the fractional sampling error is calculated accordingly. This layer-bound procedure is a reasonable first approach, which we will refine in future when we have full bending angle fields directly available.

The relation between geopotential height errors and fractional pressure errors (e.g., Kursinski et al., 1997) allows the estimation of geopotential height sampling errors. This is possible to very good accuracy since the hydrostatic balance $\mathrm{d} p / p \approx \mathrm{d} Z / H$ holds well at any UTLS altitude, where $H=\left(R_{\mathrm{d}} / g_{0}\right) T$ is the local atmospheric scale height $(\approx 7 \mathrm{~km})$, which depends on the dry air gas constant $R_{\mathrm{d}}=$ $287.06 \mathrm{~J} \mathrm{~kg}^{-1} \mathrm{~K}^{-1}$, the Earth's standard acceleration of gravity $g_{0}=9.80665 \mathrm{~m} \mathrm{~s}^{-2}$, and the temperature $T$ in Kelvin. Using this balance relation the geopotential height sampling error $Z_{\mathrm{SE}}$ is estimated from the relative pressure sampling error $p_{\mathrm{SE}}$ as

$Z_{\mathrm{SE}}=H p_{\mathrm{SE}}=\frac{R_{\mathrm{d}} T}{g_{0}} \frac{\bar{p}_{\text {coloc }}-\bar{p}_{\text {full }}}{\bar{p}_{\text {full }}}$,

where $\bar{p}_{\text {coloc }}$ is the mean of all co-located pressure profiles of a bin and $\bar{p}_{\text {full }}$ is the mean of all pressure profiles at all grid points over the full averaging period available within one bin (i.e., same meaning as $\bar{x}_{\text {coloc }}$ and $\bar{x}_{\text {full }}$ in Eq. 8).

Briefly for understanding sampling error, the sampling error can be separated into a random and a systematic component. The random component is caused by atmospheric variability, which is not adequately sampled by RO events. That is if measurements miss some part of atmospheric variability, the climatic mean is affected by a sampling error. While low atmospheric variability is captured by a smaller number of measurements, high atmospheric variability requires a larger number of measurements to reflect the "true" atmospheric mean state (e.g., high latitude winter variability will need significantly denser sampling than low latitude variability to limit the sampling error to similar magnitude). Averaging over longer timescales and/or larger spatial regions and/or increasing spatial and temporal density of observations reduces the random component of the sampling error according to the 
inverse-square-root law for averaging statistical errors like in Eq. (7) (Pirscher et al., 2007).

The systematic component of the sampling error results from systematic spatial and temporal undersampling of atmospheric variability, e.g., due to RO events never sampling certain modes of variability. As example of prime relevance, systematic undersampling of atmospheric diurnal tides due to limited local time sampling can yield a local time component error (Pirscher et al., 2007, 2010; Foelsche et al., 2009a).

Figure 2 shows sampling errors of CHAMP, GRACE-A, and F3C in October 2007, October 2008, and October 2009 as a function of latitude for each atmospheric parameter derived from RO measurements. We note that refractivity errors, given in percent, apply to dry density $\varrho_{\text {dry }}$ errors (in percent) as well since the two parameters are strictly proportional (e.g., Kursinski et al., 1997; Rieder and Kirchengast, 2001). The two blue sampling error lines from F3C that appear to exhibit some distinctively larger errors at high latitudes belong to the flight models FM-2 and FM-3. The reason is that FM-2/FM-3 incurred significant measurement gaps in October 2009/2008. The larger GRACE-A sampling error is also attributable to measurement gaps, which occurred early in October 2008.

A simple sampling error model was derived from fitting parameters of the error model given in Sect. 3 to the standard deviation of the sampling errors at all latitudes and altitudes for the different months of the seasons; Fig. 2 provides an exemplary illustration of the type of fit. Table 1 specifies the parameters obtained this way and suggested here as a simple model of the sampling error (directly applicable to the $10^{\circ}$ zonal bands). Alternatively the full climatological fields of the sampling error estimates can be used, such as supplied as part of the WEGC climatology data products.

At high latitudes beyond $40^{\circ}$ we find a strong seasonal variation of the sampling error at all altitude levels, which necessitates to model $s_{0}$ as a function of latitude and season. Therefore, we apply Eq. (3) with $x_{0}=s_{00}, \Delta x=\Delta s_{0}$ (given in Table 1), $f_{\Delta x 0}=1$, and $f_{\Delta x \mathrm{~s}}=0.25$. Parameters used in function $f(\varphi)$ are $\varphi_{\Delta s \text { lo }}=40^{\circ}$ and $\varphi_{\Delta s \mathrm{hi}}=90^{\circ}$. In other words, this model describes the sampling error to be constant at latitudes equatorwards of $40^{\circ}$ and to increase linearly with latitude from $40^{\circ}$ latitude towards the poles. $f_{\Delta x \mathrm{~s}}$ modulates this linear increase seasonally to be $25 \%$ larger in hemispheric winter and $25 \%$ smaller in hemispheric summer. We also find slightly larger sampling errors at high altitudes above $25 \mathrm{~km}$ and below $10 \mathrm{~km}$. These error increases are likely connected with larger atmospheric variability due to gravity waves in the lower stratosphere and due to more weather variations (synoptic systems, fronts, etc.) in the troposphere. The stratospheric error scale height $H_{\mathrm{S}}$, which is $25 \mathrm{~km}$ for all parameters, accounts for the increase of the sampling error in the lower stratosphere. It reflects that at $35 \mathrm{~km}$ the error is about $50 \%$ larger than in the UTLS core region below $25 \mathrm{~km}$. The error increase into the troposphere is modeled linearly $\left(b=-1\right.$; note that in this case $q_{0}$ serves
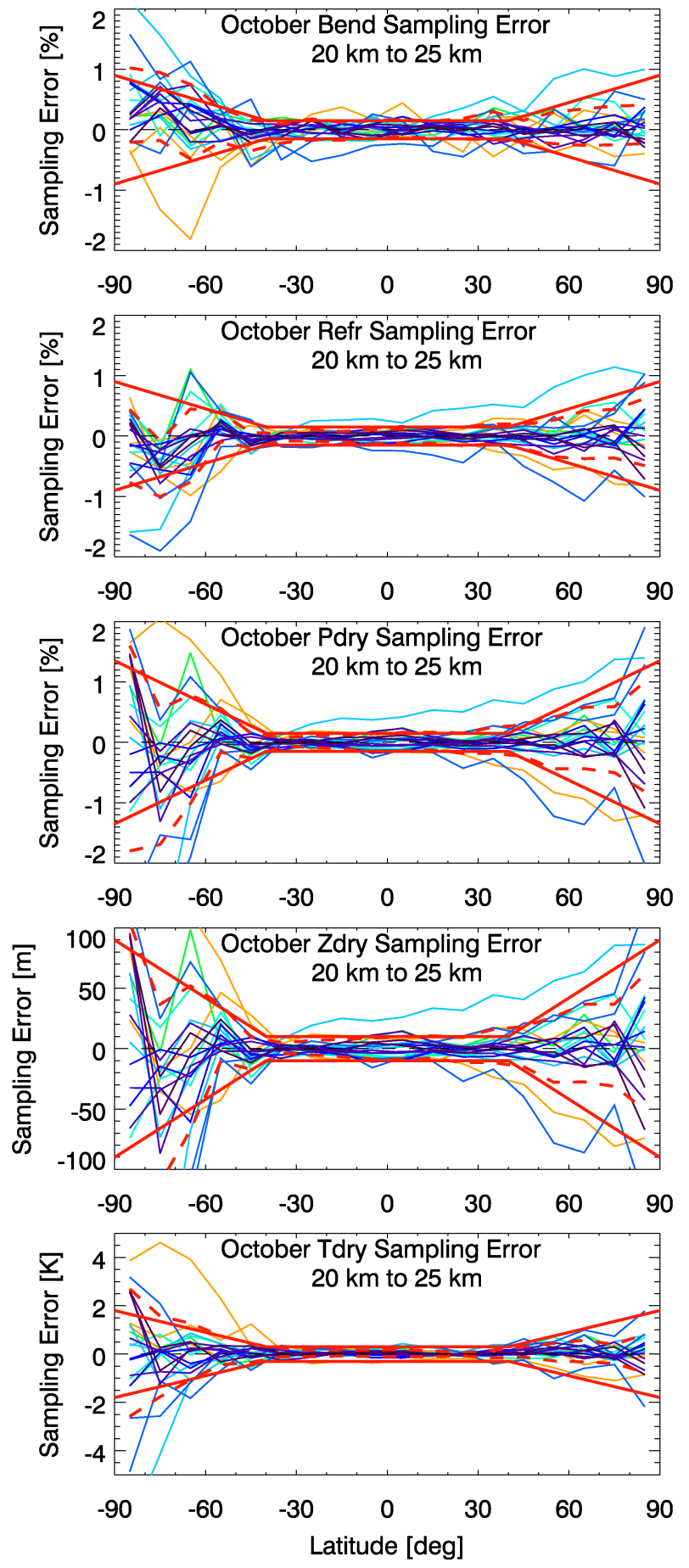

Fig. 2. Sampling errors as a function of latitude shown for October. Bending angle, refractivity, dry pressure, dry geopotential height, and dry temperature are shown from top to bottom. Monthly mean $10^{\circ}$ zonal mean sampling errors are averaged between $20 \mathrm{~km}$ and $25 \mathrm{~km}$. The standard deviation of all sampling errors (dashed) and sampling error model (solid) are drawn in red. F3C sampling errors are plotted in blue, CHAMP in green, and GRACE-A in yellow. 
Table 1. Fitting parameters for the sampling error model.

\begin{tabular}{llllllll}
\hline & $z_{\text {Ttop }}$ & $z_{\text {Sbot }}$ & \multicolumn{1}{c}{$s_{00}$} & $\Delta s_{0}$ & $q_{0}$ & $b$ & $H_{\mathrm{S}}$ \\
\hline$\alpha$ & $10.0 \mathrm{~km}$ & $25.0 \mathrm{~km}$ & $0.15 \%$ & $0.75 \%$ & $-0.012 \% \mathrm{~km}^{-1}$ & -1.0 & $25.0 \mathrm{~km}$ \\
$N, \varrho_{\text {dry }}$ & $10.0 \mathrm{~km}$ & $25.0 \mathrm{~km}$ & $0.15 \%$ & $0.75 \%$ & $-0.012 \% \mathrm{~km}^{-1}$ & -1.0 & $25.0 \mathrm{~km}$ \\
$p_{\text {dry }}$ & $10.0 \mathrm{~km}$ & $25.0 \mathrm{~km}$ & $0.15 \%$ & $1.2 \%$ & $-0.012 \% \mathrm{~km}^{-1}$ & -1.0 & $25.0 \mathrm{~km}$ \\
$Z_{\text {dry }}$ & $10.0 \mathrm{~km}$ & $25.0 \mathrm{~km}$ & $10.0 \mathrm{~m}$ & $80.0 \mathrm{~m}$ & $-0.8 \mathrm{~m} \mathrm{~km}^{-1}$ & -1.0 & $25.0 \mathrm{~km}$ \\
$T_{\text {dry }}$ & $10.0 \mathrm{~km}$ & $25.0 \mathrm{~km}$ & $0.3 \mathrm{~K}$ & $1.5 \mathrm{~K}$ & $-0.025 \mathrm{~K} \mathrm{~km}^{-1}$ & -1.0 & $25.0 \mathrm{~km}$ \\
\hline
\end{tabular}

to specify the vertical error gradient in the troposphere, see Eq. 2). At an altitude of $4 \mathrm{~km}$ the error is about $50 \%$ larger than in the UTLS core region above $10 \mathrm{~km}$.

\subsubsection{Residual sampling error}

Using OPSv5.4/CLIPSv1.3 RO climatologies provided by WEGC, sampling error estimates are available for each climatological field except for bending angle and dry geopotential height (see Sect. 4.2.1 for the derivation of bending angle and dry geopotential height sampling errors). We strongly recommend to subtract the sampling error estimates when using RO climatological fields for climate studies. Foelsche et al. (2009b, 2011a) found that climatologies from different satellites with sampling errors subtracted are in excellent agreement between $8 \mathrm{~km}$ and $35 \mathrm{~km}$ so that data of different satellites can be combined without the need of inter-calibration. However, subtracting the sampling error from a climatological field still leaves a residual sampling error. It stems from limitations of the reference atmosphere, which does not fully reflect "true" atmospheric variability.

We estimate residual sampling errors from single-satellite F3C climatologies with sampling error subtracted, the deviation to their all-satellites mean, and the respective original sampling errors themselves. Since all F3C satellites use the same kind of GPS receiver to perform their measurements, data are of the same quality and it is reasonable to assume that the differences between a climatology with sampling error subtracted and the mean are primarily caused by the residual sampling error. Thus, the ratio of the residual sampling error $s_{\mathrm{resSamplErr}, i}$ to the original sampling error $s_{\mathrm{samplErr}, i}$ of a climatology from satellite $i, r_{\text {resSamplErr }, i}$, is estimated (in percent) as

$r_{\text {resSamplErr }, i}=\frac{s_{\text {resSamplErr }, i}}{s_{\text {samplErr }, i}} \cdot 100$

where $s_{\text {resSamplErr, } i}$ in absolute terms is estimated, as outlined above, in form of the deviation of the single-satellite climatology with sampling error subtracted $x_{\mathrm{clim}, i}$ from the allsatellite-mean climatology,

$s_{\mathrm{resSamplErr}, i}=x_{\mathrm{clim}, i}-\frac{1}{n_{\mathrm{sat}}} \sum_{i=1}^{n_{\mathrm{sat}}} x_{\mathrm{clim}, i}$,

where for F3C $n_{\text {sat }}=6$ (for FM-1 to FM-6).
Note that if the original sampling error at some altitude level is incidentally very small (close to zero), which will always happen in the bins at some altitude levels, the residual sampling error ratio can formally become a very large quantity in utilizing Eq. (10) plainly. To prevent such unreasonably high $r_{\text {resSamplErr, } i}$ estimates, we implemented a minimum bound to $s_{\mathrm{samplErr}, i}$ in Eq. (10), which we set based on empirical sensitivity testing to $0.1 \%$ for bending angle, $0.03 \%$ for refractivity, $0.05 \%$ for dry pressure, $3.5 \mathrm{~m}$ for dry geopotential height, and $0.1 \mathrm{~K}$ for dry temperature. Using these minimum bounds (or values of similar size within several ten percent) for the estimations in the $10^{\circ}$ zonal bands keeps $r_{\text {resSamplErr }, i}$ magnitudes overall within about $100 \%$, in line with the basic notion that the residual error will not be higher than the original one. For being conservative, we clearly use this minimum bound also as the minimum estimate that the resulting residual sampling error can reach.

Practically in the applied error modeling it will be most convenient to use a simple scalar residual sampling error ratio $r_{\text {resSamplErr }}$ for each parameter, adopting a conservative estimate of its magnitude, to scale the original sampling error $s_{\text {samplErr }}$ from the simple model or the WEGC climatology product data to the residual sampling error $s_{\text {resSamplErr }}$ then used in Eq. (1).

Figure 3 illustrates how we derived such conservative

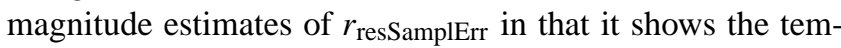
poral evolution of residual sampling error ratios for a representative zonal band and altitude layer. Smallest ratios are found for dry temperature (standard deviation near $20 \%$ ), the other parameters show standard deviations near $30 \%$. Based on this we adopt as a simple scalar estimate for $r_{\text {resSamplErr }}$ a value of $30 \%$ for all parameters.

Inspecting the behavior of $r_{\text {resSamplErr for all bins and }}$ UTLS altitudes, we find the approximation suitable everywhere for the monthly mean $10^{\circ}$ zonal mean climatologies. Also larger-scale bins like $30^{\circ}$ or $40^{\circ}$ zonal bands allow to use the same ratios; there the original sampling errors themselves are accordingly smaller due to the larger averaging areas as discussed in the previous subsection. The minimum bounds that can be adopted in this case are accordingly smaller compared to the values given above for the $10^{\circ}$ zonal bands (as we confirmed by sensitivity tests down to values of $30 \%$ of those minimum bounds for a single $120^{\circ}$ zonal band from $60^{\circ} \mathrm{S}$ to $60^{\circ} \mathrm{N}$ ). 

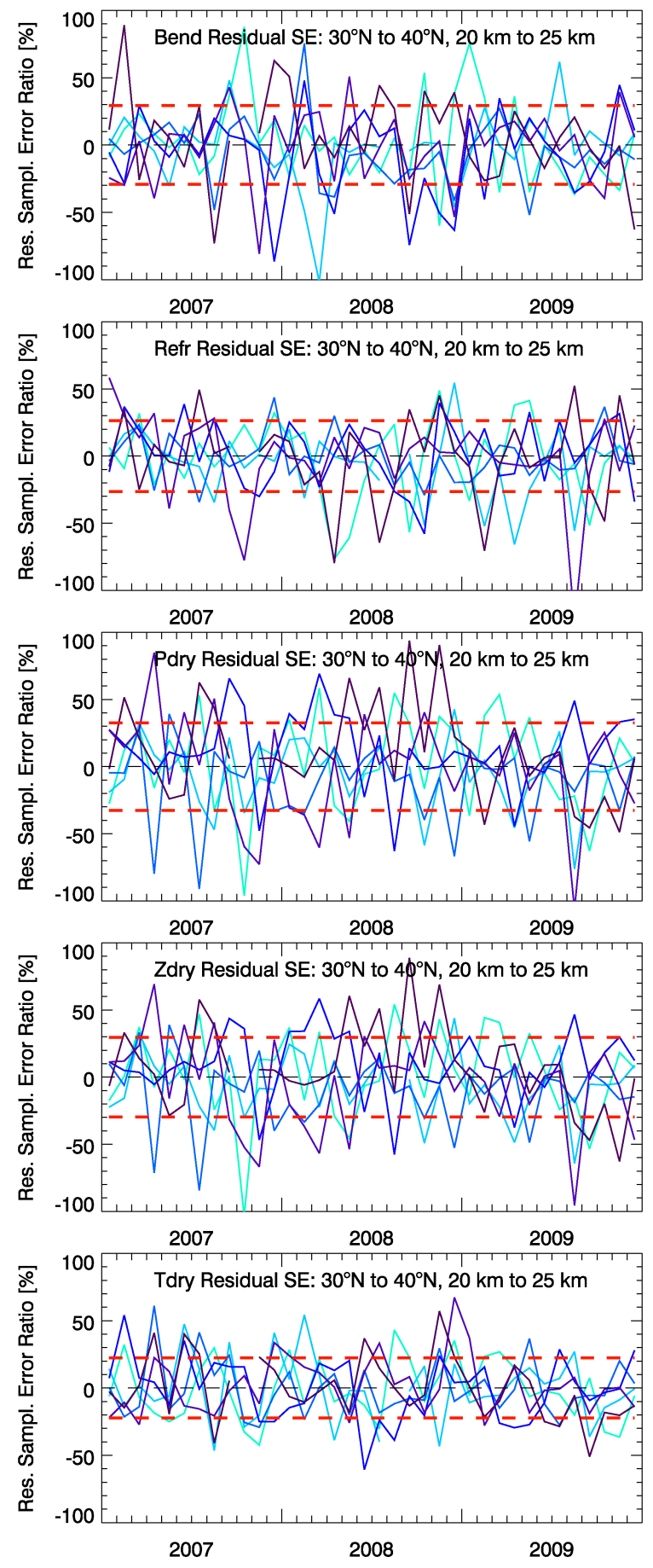

Fig. 3. Temporal evolution 2007 to 2009 of monthly residual sampling error ratios of atmospheric parameters derived from RO measurements. The ratios for bending angle, refractivity, dry pressure, dry geopotential height, and dry temperature (from top to bottom) are shown between $30^{\circ} \mathrm{N}$ and $40^{\circ} \mathrm{N}$ and between $20 \mathrm{~km}$ and $25 \mathrm{~km}$ height. Standard deviations are indicated as red-dashed horizontal lines.
We note that the residual sampling errors $s_{\text {resSamplErr }}$ obtained for Eq. (1) from using the error ratio and minimum bound values given here are fairly conservative because the empirical estimates based on Eqs. (10) and (11) still contain other error sources like some instrumental noise. Also the minimum bounds limit random error suppression.

\subsection{Discussion and modeling of the systematic error}

Systematic errors in RO climate products result from the measurements themselves as well as from assumptions made in the data processing.

Errors in excess phase measurements and orbit determination contribute to systematic measurement errors. Schreiner et al. (2009) specified uncertainties in orbit determination of the GPS and LEO satellites being low since precise position information of $<0.3 \mathrm{~m}$ and velocity information of $<0.2 \mathrm{~mm} \mathrm{~s}^{-1}$ are given. These errors cause negligible refractivity and dry temperature errors below $35 \mathrm{~km}$.

Errors due to local multipath depend on the spacecraft size and on the reflection coefficient. This error can be as large as $2 \mathrm{~mm} \mathrm{~s}^{-1}$ for large satellites and bad antenna mounting (Rocken et al., 2008), which could yield systematic refractivity and temperature errors at $25 \mathrm{~km}$ of $0.4 \%$ and $2.4 \mathrm{~K}$, respectively. However, for $\mathrm{F} 3 \mathrm{C}$ local multipath errors are estimated to be smaller than $0.05 \mathrm{~mm} \mathrm{~s}^{-1}$, which corresponds to $0.01 \%$ in refractivity and $0.06 \mathrm{~K}$ in temperature at $25 \mathrm{~km}$ (Rocken et al., 2008). Also CHAMP and GRACE-A antennae have favorable low-multipath mounting places (Wickert et al., 2001). The conversion from velocity errors to refractivity and temperature errors changes at different altitude levels; basically it decreases exponentially downwards.

Errors caused by assumptions in the inversion process yield systematic errors in RO inversion products of bending angle, refractivity, dry pressure, dry geopotential height, and dry temperature as well as their derived climate products.

Atmospheric excess phase measurements do not only include the neutral atmospheric excess phase path, but also an ionospheric contribution, which has to be removed in the RO retrieval. Most RO processing chains apply the ionospheric correction at bending angle level (Ho et al., 2009), where a linear combination of L1 and L2 bending angle profiles (Vorob'ev and Krasil'nikova, 1994) removes the ionospheric effect to the first order. The level of ionization and therefore residual ionospheric errors are correlated with solar activity. Residual ionospheric errors under solar maximum conditions are larger than errors under solar minimum conditions. This bending angle change, which is associated with the 11-yr solar cycle, was estimated to induce a temperature error of up to $0.1 \mathrm{~K}$ at $20 \mathrm{~km}$ and $0.5 \mathrm{~K}$ at $30 \mathrm{~km}$ during the day while during the night this error decreased to $0.002 \mathrm{~K}$ at $20 \mathrm{~km}$ and $0.01 \mathrm{~K}$ at $30 \mathrm{~km}$ (Rocken et al., 2009). Given careful quality control for climate applications (including, e.g., exclusion of events under highest ionization conditions from 
Table 2. Model parameters for the systematic error modeling.

\begin{tabular}{llllllll}
\hline & $z_{\text {Ttop }}$ & $z_{\text {Sbot }}$ & $s_{00}$ & $\Delta s_{0}$ & $q_{0}$ & $b$ & $H_{\mathrm{S}}$ \\
\hline$\alpha$ & $10.0 \mathrm{~km}$ & $20.0 \mathrm{~km}$ & $0.1 \%$ & $0.05 \%$ & $-0.02 \% \mathrm{~km}^{-1}$ & -1.0 & $18.0 \mathrm{~km}$ \\
$N, \varrho_{\text {dry }}$ & $10.0 \mathrm{~km}$ & $20.0 \mathrm{~km}$ & $0.05 \%$ & $0.025 \%$ & $-0.01 \% \mathrm{~km}^{-1}$ & -1.0 & $15.0 \mathrm{~km}$ \\
$p_{\text {dry }}$ & $10.0 \mathrm{~km}$ & $20.0 \mathrm{~km}$ & $0.1 \%$ & $0.05 \%$ & $-0.01 \% \mathrm{~km}^{-1}$ & -1.0 & $11.0 \mathrm{~km}$ \\
$Z_{\text {dry }}$ & $10.0 \mathrm{~km}$ & $20.0 \mathrm{~km}$ & $7.0 \mathrm{~m}$ & $3.5 \mathrm{~m}$ & $-0.6 \mathrm{~m} \mathrm{~km}^{-1}$ & -1.0 & $11.0 \mathrm{~km}$ \\
$T_{\text {dry }}$ & $10.0 \mathrm{~km}$ & $20.0 \mathrm{~km}$ & $0.1 \mathrm{~K}$ & $0.05 \mathrm{~K}$ & $-0.012 \mathrm{~K} \mathrm{~km}^{-1}$ & -1.0 & $11.0 \mathrm{~km}$ \\
\hline
\end{tabular}

climatological averages) these daytime estimates are likely conservative by a factor of two or three, however.

Another systematic error component results from the background information-dependent initialization of bending angle profiles, which is crucial to eliminate large bending angle noise at high altitudes (Gobiet and Kirchengast, 2004). The RO data noise level and the quality of the background climatology determine the magnitude of this error (Gobiet and Kirchengast, 2004; Kuo et al., 2004; Gobiet et al., 2007; Foelsche et al., 2011a). Due to worst quality of background climatologies, largest errors typically occur at high latitudes. However, the error decreases with altitude and is, in general, small ( $<0.2 \mathrm{~K}$ in large-scale non-polar regions) below $30 \mathrm{~km}$ (Gobiet et al., 2007).

Other systematic errors can result from the spherical symmetry assumption made in the retrieval. Even though the magnitude of this error is unknown at the current stage, it is assumed to be small (Rocken et al., 2008), at least above the lower troposphere in focus here. Higher latitudes may generally see somewhat larger sustained spherical asymmetries than lower and mid latitudes, e.g., due to slowly varying polar vortex boundaries or stratospheric warming patterns during winter. Systematic errors in the lower troposphere also can result from strong horizontal refractivity gradients (Healy, 2001), tracking errors (Beyerle et al., 2003), and super-refraction (Sokolovskiy, 2003). Lower tropospheric systematic errors are also tentatively caused by the degrading quality of the GPS L2 signal.

To include simple modeling of a reasonable upper bound estimate of systematic climatological errors, we again apply the model formulation given in Eqs. (2) and (3). Parameter values we adopted are specified in Table 2 . The values were chosen to reflect up-to-date best guesses of systematic error bounds based on the arguments and discussion of systematic error sources given above. Overall the dominating contribution increasing the error exponentially upwards in the lower stratosphere is initialization error, including also some part of residual ionospheric errors. The main contributions increasing the error downwards into the troposphere are stronger horizontal gradients that are challenging to signal tracking and processing (most important in very moist regions, i.e., at low latitudes below approximately $8 \mathrm{~km}$; Sokolovskiy, 2001; Anthes et al., 2008) as well as generally degraded GPS L2 signal quality. In between these upper and lower altitude domains the systematic errors are smallest.

Based on these considerations we specify the systematic error to be constant in the core region between $10 \mathrm{~km}$ and $20 \mathrm{~km}$ and to increase above and below. Pressure and geopotential height errors in the UTLS region are assumed to be somewhat larger than that for other atmospheric parameters because they strongly depend on the accuracy of the geopotential height leveling, which is assumed limited to $\approx 7 \mathrm{~m}$ (e.g., Kursinski et al., 1997; Leroy, 1997). Assuming a typical atmospheric scale height of $7 \mathrm{~km}$, a systematic leveling error of $7 \mathrm{~m}$ corresponds to a systematic pressure error of $0.1 \%$. Due to less dependence on leveling errors, refractivity and dry temperature systematic errors are estimated smaller; their relation via a factor of 2 between relative refractivity and absolute temperature errors is well established theoretically and empirically (see Scherllin-Pirscher et al., 2011). The linear increase of the error $(b=-1)$ below $10 \mathrm{~km}$ into the troposphere (by $50 \%$ or more down to $4 \mathrm{~km}$ ) is mainly attributed to horizontal gradients leading to more deviation from spherical symmetry and more complex signal propagation (e.g., multipath), tracking and retrieval, and degraded GPS L2 signal quality. Residual ionization errors and errors in the background atmosphere used for initialization of the Abel integral cause an exponential increase of the systematic error in the lower stratosphere region. Stratospheric error scale heights are therefore set larger (smaller systematic error) in bending angle and refractivity and smaller (larger systematic errors) in dry pressure, dry geopotential height, and dry temperature. These values reflect that systematic errors, similar to statistical errors (Scherllin-Pirscher et al., 2011), propagate increasingly further down via the Abelian integral and, subsequently, the hydrostatic integral (e.g., Rieder and Kirchengast, 2001; Steiner and Kirchengast, 2005).

During the winter months systematic errors beyond $50^{\circ}$ are modeled larger due to the worse quality of the background atmosphere for initialization, polar vortex structures causing increased polar winter variability, more sustained horizontal asymmetries at vortex edges, and sudden stratospheric warming patterns. To account for these latitudinal and seasonal variations, $s_{0}$ is modeled by Eq. (3) using $\Delta s_{0}=0.5 s_{00}, f_{\Delta x 0}=1$, and $f_{\Delta x \mathrm{~s}}=1$. In function $f(\varphi)$, $\varphi_{\Delta x \mathrm{lo}}=50^{\circ}$ and $\varphi_{\Delta x \mathrm{lo}}=60^{\circ}$. Taking these settings the 
values $f_{\Delta x 0}$ and $f_{\Delta x \mathrm{~s}}$ are evidently chosen in a way so that $s_{0}$ is twice as large during hemispheric winter at high latitudes beyond $60^{\circ}$ than at lower latitudes. In the summer hemisphere, however, $s_{0}$ is the same at lower and high latitudes.

Looking at systematic errors as modeled in this way in the context of long-term stability, it is assumed that they also bound the systematic trend uncertainty per decade (e.g., temperature stability better than $0.1 \mathrm{~K}$ per decade), consistent with structural uncertainty estimates by Ho et al. (2009) and with estimates based on more than seven years of RO data from six processing centers (Steiner et al., International RO Trends Intercomparison Group, personal communications, 2011).

We note that the systematic error estimates in Table 2 do not explicitly include possible remaining absolute long-term constant offsets to the fundamental SI scale (e.g., due to time offsets and related geometrical orbit position uncertainties). These offsets would not influence climatic trend estimates but matter if RO data are compared to data from other instruments on an absolute scale (e.g., temperatures of radiosondes and RO compared in units Kelvin). Such systematic uncertainties could be in principle due to fundamental uncertainty in orbit determination (as mentioned above), in the vertical coordinate frame (Earth's figure reference leveling), and from uncertainties in coefficients of the refractivity equation.

Regarding orbits, modern precise orbit determination (POD) sustainably produces absolute positions (in inertial or Earth-bound frame) better than $1 \mathrm{~m}$ as discussed further above. Regarding vertical reference frames, the WGS-84 ellipsoid is used for the Earth figure, and the EGM-96 geoid (or a better one) for conversion of ellipsoidal height to m.s.l. altitude. The accuracy of the WGS-84 coordinate system is within $1 \mathrm{~m}$ (http://earth-info.nga.mil/GandG/publications/ tr8350.2/tr8350_2.html) (NIMA, 2000) and also geoid undulations are accurate to better than $1 \mathrm{~m}$ in the NASA GSFC and NIMA Joint Geopotential Model EGM-96 (http://cddis. nasa.gov/926/egm96/nasatm.html) (Lemoine et al., 1998) or newer models. All these sub-meter effects are negligible within the systematic error budgets specified by Table 2 and thus tacitly co-accounted for by those error bound estimates.

The accuracy of all natural or derived constants as used in the processing of RO parameters is very high and given to an accuracy of at least $10^{-4}$ to $10^{-5}$ except for the refractivity coefficients. Healy (2011) investigated the influence of different values of the refractivity coefficient $k_{1}=$ $77.643 \mathrm{~K} \mathrm{hPa}^{-1}$ (Rüeger, 2002, adjusted for non-ideal gas effects) versus $k_{1}=c_{1}=77.60 \mathrm{~K} \mathrm{hPa}^{-1}$ (Smith and Weintraub, 1953). His findings showed that a larger $k_{1}$ results in a systematically larger bending angle of $0.115 \%$ in the UTLS which affects the tropospheric temperature by $-0.1 \mathrm{~K}$ (refractivity by $0.05 \%$ ). Overall these constant systematic errors are comparable to the systematic error estimates in Table 2 so that a conservative approach might be to increase those by a square-root-of-two factor if an application (e.g., a cross-validation) shall account for comparison at an absolute scale.

\subsection{Total climatological error}

The total climatological error $s_{\text {totErr }}$ includes all individual error components described above. The modeling of the total climatological error thus contains the models of these individual components, which are added in terms of variances as expressed by Eq. (1). Based on the formulation and the related parameters given for the simple empirical-analytical modeling, the implementation of $s_{\text {totErr }}$ as a function of altitude, latitude, and season is fairly straightforward for use in any application of RO climatological fields. Also the alternative use of full fields of statistical errors and sampling errors, such as supplied as part of WEGC climatology data products, in even more realistic error modeling is not difficult to implement. Here we illustrate and briefly discuss the errors obtained.

Figure 4 shows the total climatological error model and its components for two zonal bands of different width as observed in October under mean stratospheric conditions. The statistical error modeling utilizes the error model detailed in Scherllin-Pirscher et al. (2011) and uses parameters as given therein for WEGC data. Since the statistical error strongly depends on the number of measurements (cf. Eq. 7), it is plotted for 200 and 600 events in the $10^{\circ}$-zonal band for representing CHAMP/GRACE-A and $\mathrm{F} 3 \mathrm{C}$, respectively, and for 600 and 1800 events in the $30^{\circ}$-zonal band. The statistical error evidently decreases with increasing number of measurements according to Eq. (7).

Averaging over several $10^{\circ}$-zonal bands also reduces the residual sampling error, which decreases by the square root of the number of averaged bins. This rate of error reduction holds true if the number of measurements is equally distributed over all latitudes bands, which is not entirely true at high latitudes. The systematical error, however, does not decrease when using larger regions.

The dominant error component of the total climatological error is generally the systematic error estimate at all altitude levels and for all atmospheric parameters. In bending angle and refractivity, the statistical error and the residual sampling error are of the same order of magnitude for $10^{\circ}$ zonal bins. In dry pressure, dry geopotential height, and dry temperature, the residual sampling error is larger than the statistical error.

In the altitude range between $10 \mathrm{~km}$ and $20 \mathrm{~km}$ at high latitudes during wintertime, the total climatological error of monthly mean $10^{\circ}$ zonal mean single-satellite climatologies can be as large as about $0.4 \%, 0.3 \%, 0.5 \%, 35 \mathrm{~m}$, and $0.6 \mathrm{~K}$ in bending angle, refractivity, dry pressure, dry geopotential height, and dry temperature, respectively. At low latitudes equatorwards of $30^{\circ}$, however, the total error remains smaller than $0.15 \%$ in bending angle, $0.07 \%$ in refractivity, $0.12 \%$ in dry pressure, $8 \mathrm{~m}$ in dry geopotential height, and $0.15 \mathrm{~K}$ in dry temperature. Overall the errors of RO climatological 

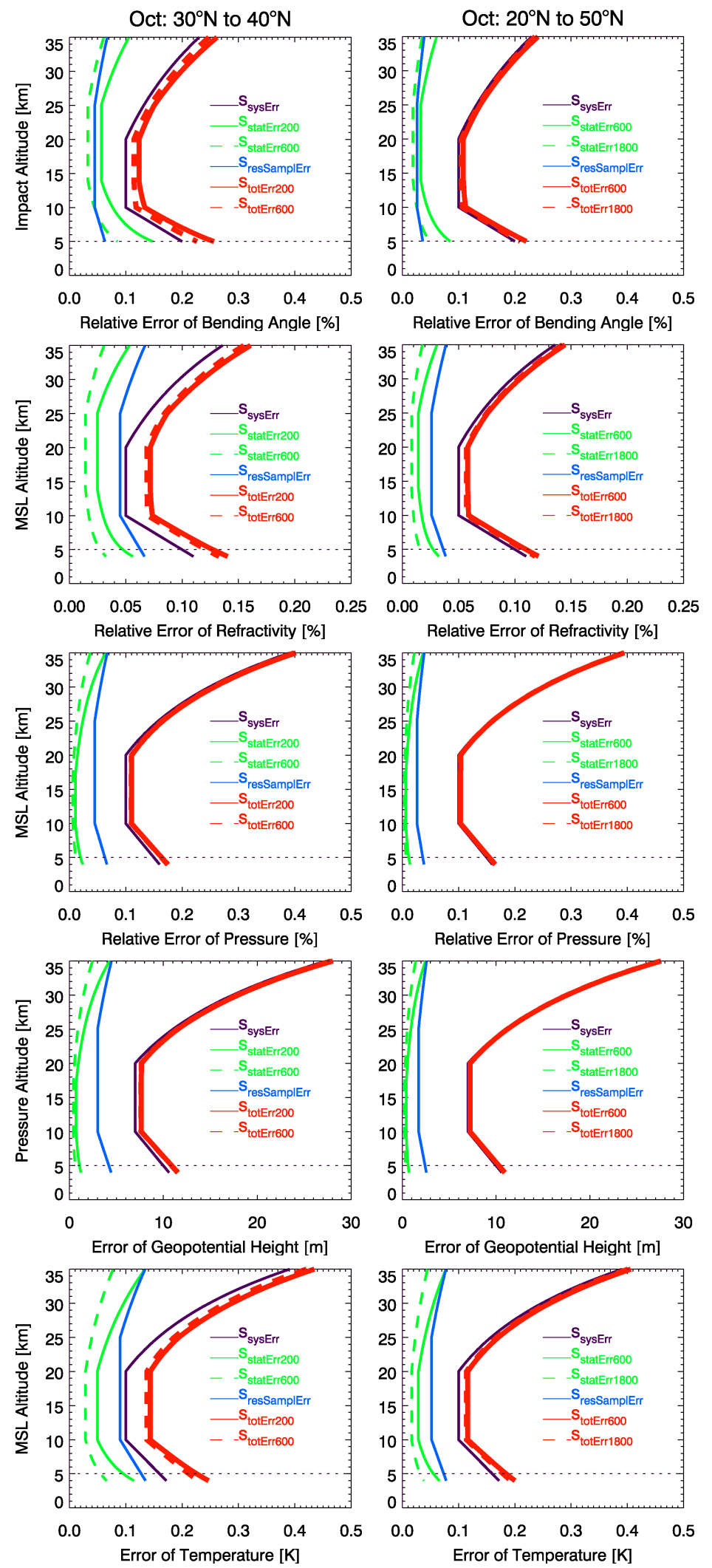

Fig. 4. Total climatological error (red) and its components: Systematic error (purple), statistical error (green), and residual sampling error (blue) are shown for bending angle, refractivity, dry pressure, dry geopotential height, and dry temperature (from top to bottom). Model results reflect mean stratospheric conditions as observed in October (and April). Left column: results for a $10^{\circ}$-zonal band between $30^{\circ} \mathrm{N}$ and $40^{\circ} \mathrm{N}$. Right column: results in the Northern Hemisphere mid-latitude band between $20^{\circ} \mathrm{N}$ and $50^{\circ} \mathrm{N}$. 

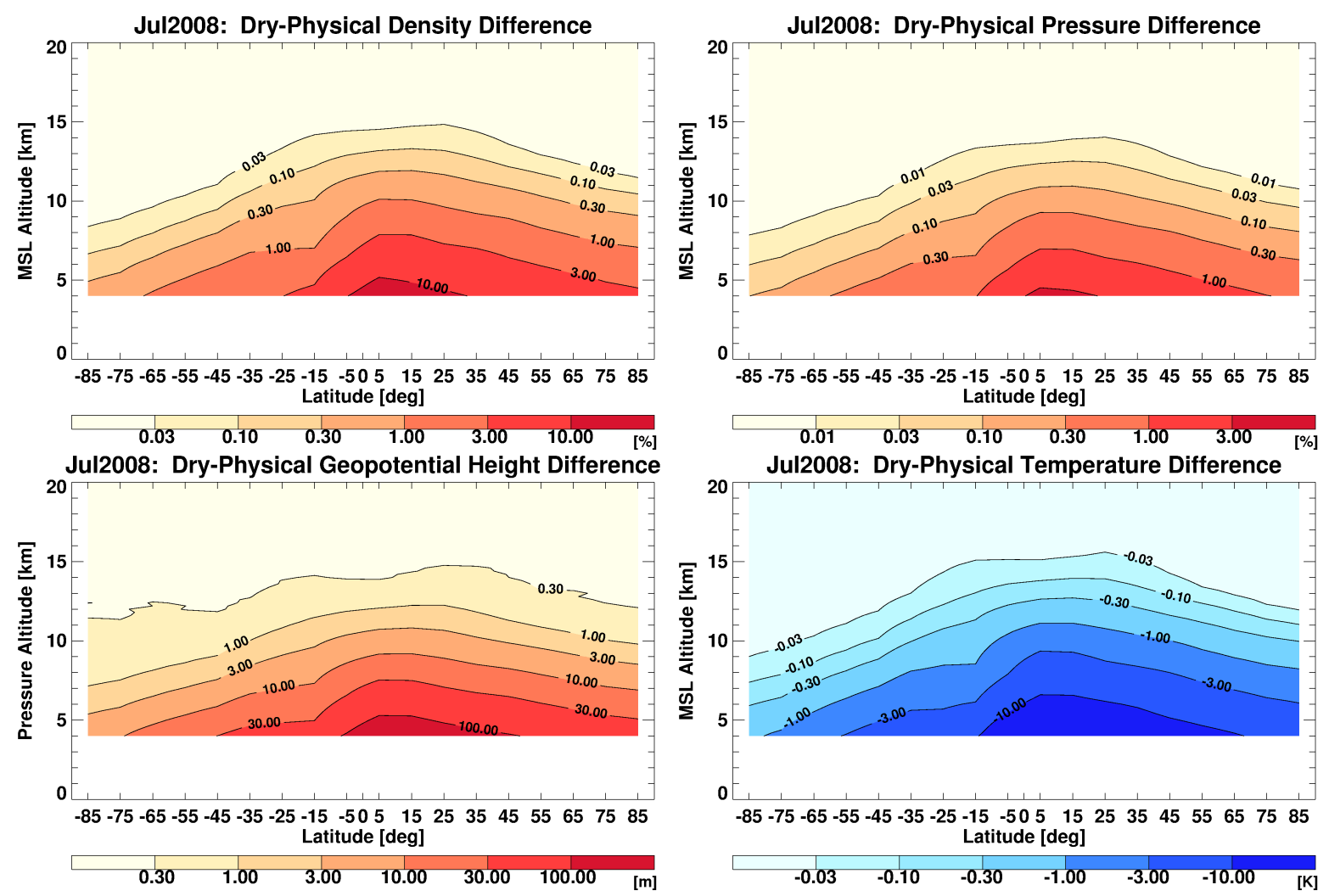

Fig. 5. Difference between dry and physical atmospheric parameters for density, pressure (top panels), geopotential height, and temperature (bottom panels) for a zonal mean climatological field of July 2008.

fields are evidently very small compared to any other UTLS observing system for thermodynamic atmospheric variables, making these data particularly valuable as a reference data set.

\section{Representativeness of dry for actual parameters}

After discussing the error modeling for RO dry atmospheric parameters it is finally useful for non-RO-expert data users to put these RO-specific parameters in quantitative context with actual physical parameters. That is, the relation of dry density, dry pressure, dry geopotential height, and dry temperature to actual air density, pressure, geopotential height, and temperature is of interest to ensure proper understanding and use of the dry parameters for example in comparison to measurements of physical parameters from other instruments.

The core RO variable is refractivity at microwave wavelengths derived from GPS measurements, which characteristically depends on dry and moist atmospheric conditions. This relationship is, for the region above $4 \mathrm{~km}$ in focus here, well given by (Smith and Weintraub, 1953; Kursinski et al., 1997)
$N=c_{1} \frac{p}{T}+c_{2} \frac{e}{T^{2}}$,

where $p$ is atmospheric pressure (in $\mathrm{hPa}$ ), $T$ temperature (in $\mathrm{K}$ ), and $e$ partial pressure of water vapor (in $\mathrm{hPa}$ ). The accuracy of the constants $c_{1}=77.60 \mathrm{~K} \mathrm{hPa}^{-1}$ and $c_{2}=3.73 \times$ $10^{5} \mathrm{~K}^{2} \mathrm{hPa}^{-1}$ has already been addressed in Sect. 4.3; for more details see, e.g., Rüeger (2002) and Healy (2011).

The first and the second terms in Eq. (12) represent the refraction contribution of induced polarization of all air molecules ("dry term") and of orientation polarization of the water vapor molecules ("wet term"), respectively. In a dry air with no (negligible) water vapor the second term is (essentially) zero. Formally neglecting the second term notwithstanding whether the air is dry or moist yields dry atmospheric parameters. Evidently, then, in regions with negligible moisture dry RO parameters will equal physical parameters but in regions with significant moisture they will deviate; and for high water vapor concentrations in the lower troposphere this difference between dry and physical parameters will even become large (e.g., Kursinski et al., 1997; Foelsche et al., 2008).

Figure 5 quantitatively illustrates the difference between dry and physical atmospheric parameters for Northern Hemisphere summer conditions (Southern Hemisphere summer conditions would have the distribution of differences 
correspondingly skewed towards the Southern Hemisphere and spring/fall conditions would lead it to be essentially symmetric about the equator).

It can be seen that above $\approx 14 \mathrm{~km}$ at low latitudes and $\approx 9 \mathrm{~km}$ at high latitudes dry atmospheric parameters are essentially equal to physical parameters (within RO climatological errors) but the difference increases noticeable downwards into the troposphere, governed by the increase of moisture. We furthermore see that dry density, pressure, and geopotential height are always larger than their physical equivalents, while dry temperature is smaller (cooler) than physical temperature. Comparison of RO dry parameters with corresponding physical parameters from other sources, or using them as direct proxies for the physical parameters, will thus in the troposphere always have to be aware of the systematic differences of the typical size illustrated in Fig. 5. As an example, Steiner et al. (2009) used dry temperature in the tropics within the $300 \mathrm{hPa}$ to $200 \mathrm{hPa}$ layer $(\approx 9.5 \mathrm{~km}$ to $12.5 \mathrm{~km}$ ) to study upper troposphere temperature trends; this was valid only given that a thorough understanding of how dry temperature trends represented physical temperature trends had been established as integral part of the study.

To allow quantitative understanding of this difference behavior and its co-modeling in some applications, we derive here the relationships between dry and physical parameters. For this purpose we equate the dry term of refractivity, defining the dry RO parameters, with the complete formulation of Eq. (12),

$c_{1} \frac{p_{\text {dry }}}{T_{\text {dry }}} \stackrel{!}{=} c_{1} \frac{p}{T}+c_{2} \frac{e}{T^{2}}=c_{1} \frac{p}{T}\left(1+\frac{c_{\mathrm{V} 2 \mathrm{~T}} V_{\mathrm{w}}}{T}\right)$,

where $V_{\mathrm{w}}=e / p$ is the water vapor volume mixing ratio and $c_{\mathrm{V} 2 \mathrm{~T}}=c_{2} / c_{1}=4806.7 \mathrm{~K} /(\mathrm{hPa} / \mathrm{hPa})$ is the scaling factor converting $V_{\mathrm{w}}$ to the temperature scale $(\approx 4.8 \mathrm{~K}$ per $1000 \mathrm{ppmv})$.

Rearranging this equation for $T_{\text {dry }}$ and $p_{\text {dry }}$ yields

$T_{\text {dry }}=\frac{p_{\text {dry }}}{p}\left(\frac{T}{1+\frac{c_{\mathrm{V} 2 T} V_{\mathrm{W}}}{T}}\right) \approx \frac{p_{\mathrm{dry}}}{p} T-c_{\mathrm{q} 2 \mathrm{~T} q}$,
$p_{\text {dry }}=p \frac{T_{\mathrm{dry}}}{T}\left(1+\frac{c_{\mathrm{V} 2 \mathrm{~T}} V_{\mathrm{W}}}{T}\right) \approx p \frac{T_{\mathrm{dry}}+c_{\mathrm{q} 2 \mathrm{~T}} q}{T}$,

where $q$ is the specific humidity (in $\mathrm{kg} \mathrm{kg}^{-1}$ ) and $c_{\mathrm{q} 2 \mathrm{~T}}=$ $c_{\mathrm{V} 2 \mathrm{~T}} / a_{\mathrm{w}}=7728 \mathrm{~K} /(\mathrm{kg} / \mathrm{kg}$ ) (including the dry air to water vapor gas constant ratio $a_{\mathrm{w}}=0.622$ ) is the scaling factor con-

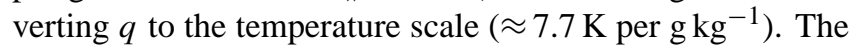
approximate expressions in Eqs. (14) and (15) assume that $c_{\mathrm{V} 2 \mathrm{~T}} V_{\mathrm{W}} / T \approx c_{\mathrm{q} 2 \mathrm{~T}} q / T \ll 1$ and, for the first order moistureinduced temperature increment $c_{\mathrm{q} 2 \mathrm{~T}} q$, that $\left(p_{\mathrm{dry}} / p\right) c_{\mathrm{q} 2 \mathrm{~T}} q \approx$ $\left(T_{\text {dry }} / T\right) c_{\mathrm{q} 2 \mathrm{~T}} q \approx c_{\mathrm{q} 2 \mathrm{~T}} q$. These approximations keep the expressions accurate up to second order down to $4 \mathrm{~km}$ and more clearly show the essential physical relations.

Using the relations above we can express the dry increments $T_{\mathrm{dry}}-T$ and $\left(p_{\mathrm{dry}}-p\right) / p$ as

$$
\begin{aligned}
T_{\mathrm{dry}}-T & \approx T\left(\frac{p_{\mathrm{dry}}-p}{p}-\frac{c_{\mathrm{q} 2 \mathrm{~T}} q}{T}\right) \\
& =-c_{\mathrm{q} 2 \mathrm{~T}} q\left(1-\frac{\left(p_{\mathrm{dry}}-p\right) / p}{\left(c_{\mathrm{q} 2 \mathrm{~T}} q\right) / T}\right) \\
\frac{p_{\mathrm{dry}}-p}{p} & \approx \frac{\left(T_{\mathrm{dry}}+c_{\mathrm{q} 2 \mathrm{~T}} q\right)-T}{T},
\end{aligned}
$$

which now can be used to quantitatively understand Fig. 5 . The ratio of pressure to temperature fractional increments in the rightmost parenthesis of Eq. (16) is roughly constant everywhere and amounts to $\approx 0.2$ (can be checked by, e.g., plotting it as a field, which shows it varies within about $25 \%$ only at all relevant altitudes up to where the difference of physical and dry temperature drops well below $0.1 \mathrm{~K}$ ). Therefore a good basic estimate for the dry temperature increment is $T_{\mathrm{dry}}-T \approx-\frac{4}{5} c_{\mathrm{q} 2 \mathrm{~T}} q$. Using this in Eq. (17) yields equally simple basic estimates for the dry pressure increment, $\left(p_{\text {dry }}-p\right) / p \approx \frac{1}{5}\left(c_{\mathrm{q} 2 \mathrm{~T}} q\right) / T \approx-\frac{1}{4}\left(T_{\mathrm{dry}}-T\right) / T$. Turning to Fig. 5 we can now explain the dry pressure and temperature differences shown. As an example, if we inspect the dry pressure increment near $7 \mathrm{~km}$ in the tropics we find it to be about $1 \%$ there and the related dry temperature increment somewhere near $8 \mathrm{~K}$. Using a reasonable temperature of $260 \mathrm{~K}$ for this location shows that the simple estimates are valid to connect the increments. Using also reasonable specific humidity near $1.3 \mathrm{~g} \mathrm{~kg}^{-1}$ (converting to a moistureinduced increment $c_{\mathrm{q} 2 \mathrm{~T}} q$ of near $10 \mathrm{~K}$ ) and employing the full equations again shows their utility, including that the sign of the increments becomes clearly understood.

Based on the dry temperature and pressure increments we can also formulate the dry density and geopotential height increments, $\left(\varrho_{\mathrm{dry}}-\varrho\right) / \varrho$ and $Z_{\mathrm{dry}}-Z$, by using the equation of state and the hydrostatic balance in differential form, $\mathrm{d} \varrho / \varrho=\mathrm{d} p / p-\mathrm{d} T / T$ and $\mathrm{d} Z / H=\mathrm{d} p / p$ (cf. Eq. 9), which yields

$$
\begin{aligned}
& \frac{\varrho_{\mathrm{dry}}-\varrho}{\varrho} \approx \frac{p_{\mathrm{dry}}-p}{p}-\frac{T_{\mathrm{dry}}-T}{T} \approx \frac{c_{\mathrm{q} 2 \mathrm{~T}} q}{T}, \\
& Z_{\mathrm{dry}}-Z \approx H_{\mathrm{pTq}} \frac{p_{\text {dry }}-p}{p},
\end{aligned}
$$

where $H_{\mathrm{pTq}}$ in Eq. (19) is an effective scale height amounting roughly to $4 \mathrm{~km}$. This can be checked by, e.g., plotting $H_{\mathrm{pTq}} \approx p\left(Z_{\mathrm{dry}}-Z\right) /\left(p_{\mathrm{dry}}-p\right)$ as a field, which shows it varies by up to about $50 \%$ though. The reason is that it is influenced in particular by humidity gradients $\mathrm{d} q / \mathrm{d} z$, on top of depending on pressure and temperature, given the vertical dry pressure increment gradient can be estimated from the simple formulae above as $\mathrm{d}\left(p_{\mathrm{dry}}-p\right) / \mathrm{d} z \approx$ $\frac{1}{5} c_{\mathrm{q} 2 \mathrm{~T}}(p / T)(\mathrm{d} q / \mathrm{d} z)$; a more detailed description of this is left for future work.

Comparing Eq. (18) with the estimates for pressure and temperature above leads to the basic simple estimate $\left(\varrho_{\text {dry }}-\right.$ 
$\varrho) / \varrho \approx 5\left(p_{\text {dry }}-p\right) / p$ for the dry density increment, which is also well confirmed by Fig. 5 (top left vs. top right panel). The basic estimate for the dry geopotential height increment is $Z_{\text {dry }}-Z(\mathrm{~m}) \approx 40\left(p_{\text {dry }}-p\right) / p(\%)$ (analogous to Eq. 9 but the effective scale height here being around $4 \mathrm{~km}$ ). Fig. 5 (top right vs. bottom left panel) confirms this relation.

Overall the above relations and Fig. 5 provide a clear basis to understand and properly use RO dry parameters and their associated error estimates derived in this paper in the context of applications involving also the physical parameters. The upcoming version of the WEGC RO processing past OPSv5.4 will provide both dry and physical parameters (the latter derived by optimal estimation including background information from short-term forecasts in the troposphere), together with separate error estimates also for the physical parameters.

\section{Summary and conclusions}

Radio occultation (RO) measurements are known to be of very high accuracy, offer a high vertical resolution, are available globally, are self-calibrating and therefore long-term stable. Data of different satellite missions can be combined without the need of inter-calibration, provided that the same processing scheme (up to negligible differences in raw processing) has been used (Foelsche et al., 2009b, 2011b). These characteristics qualify RO data to be very useful for climate studies.

RO climatologies of different atmospheric parameters like bending angle, refractivity, density, pressure, geopotential height, and temperature can be calculated from RO profiles. RO climatologies are affected by random (statistical) errors, (residual) sampling errors, and systematic errors. The error components together contribute to the total climatological error. Based on the empirically derived error models provided by Steiner and Kirchengast (2005), Steiner et al. (2006), and Scherllin-Pirscher et al. (2011), this study provided a simple empirical-analytical error model for these climatological error components, which accounts for vertical, latitudinal, and seasonal variations. It is straightforward to use for any application of RO climatological fields and versatile in adjusting its parameters as needed to different data sets. Also the alternative use of full fields of statistical errors and sampling errors, such as supplied as part of WEGC climatology data products, in even more realistic error modeling is well possible.

Around the tropopause region (a few kilometers below and above), a constant error is adopted in the simple model. Below this region the error increases following an inverse height power-law, above this region it increases exponentially. To account for latitudinal and seasonal variations, the model utilizes mean atmospheric conditions, maximum amplitudes, as well as simple dependencies on latitude (lower and higher latitude regimes and linear transition in between) and season (cosine variation according to the annual cycle).

The statistical error is modeled using the observational error model as described by Scherllin-Pirscher et al. (2011), and the number of profiles per bin. The error decreases with the square root of the number of measurements and is found to be the smallest error component for monthly mean $10^{\circ}$ zonal mean climatologies with sampling error subtracted, which receive more than about 600 measurements per bin.

The sampling error is found to be roughly constant at low latitudes equatorwards of $40^{\circ}$. Beyond $40^{\circ}$, the error increases roughly linearly. This increase is larger by $25 \%$ in the winter hemisphere than in the summer hemisphere. Subtracting the sampling error from raw RO climatologies, which is highly recommended, still leaves a residual sampling error, which stems from reference atmosphere data used for sampling error estimation, which do not reflect true atmospheric variability. The residual sampling error is estimated to be approximately $30 \%$ or less of the original sampling error for all atmospheric parameters. In context with the other errors, the residual sampling error is typically of the same order of magnitude as the statistical error.

The systematic climatological error, which accounts for potential residual biases in the measurements as well as in the retrieval process, is the dominating error source of the total climatological error. In the altitude range between $10 \mathrm{~km}$ and $20 \mathrm{~km}$ at low latitudes (and at high latitudes during wintertime as worst case) the total climatological error of monthly mean $10^{\circ}$ zonal mean single-satellite climatologies amounts to about $0.12 \%(0.4 \%)$ in bending angle, $0.07 \%(0.3 \%)$ in refractivity, $0.12 \%(0.5 \%)$ in dry pressure, $8 \mathrm{~m}(30 \mathrm{~m})$ in dry geopotential height, and $0.15 \mathrm{~K}(0.6 \mathrm{~K})$ in dry temperature. Overall the errors of RO climatological fields are found very small compared to any other UTLS observing system for thermodynamic atmospheric variables, making these data particularly valuable as a reference data set.

Complementing the discussion of the error modeling for dry atmospheric parameters, these $\mathrm{RO}$-specific parameters were finally put into quantitative context with actual physical parameters. The relations of dry density, dry pressure, dry geopotential height, and dry temperature to actual air density, pressure, geopotential height, and temperature were derived and discussed to ensure proper understanding and use of the dry parameters in studies including both dry and physical parameters.

Acknowledgements. We thank ECMWF (Reading, UK) for providing analysis data. Furthermore we are grateful to the UCAR/CDAAC and WEGC GPS RO operational team members, at WEGC especially to J. Fritzer and F. Ladstädter, for their contributions in OPS system development and operations. We also thank C. Rocken at UCAR for helpful discussions. AKS was funded by the Austrian Science Fund (FWF) under grant P21642-N21 (TRENDEVAL project) and the work was also co-funded by grant P22293-N21 (BENCHCLIM project). WEGC OPS development was co-funded by ESA/ESTEC Noordwijk, ESA/ESRIN Frascati, 
and FFG/ALR Austria. At UCAR the work was supported by the National Science Foundation under Cooperative Agreement No. AGS-0918398/CSA No. AGS-0939962. The National Center for Atmospheric Research is supported by the National Science Foundation.

Edited by: K. B. Lauritsen

\section{References}

Anthes, R. A., Bernhardt, P. A., Chen, Y., Cucurull, L., Dymond, K. F., Ector, D., Healy, S. B., Ho, S.-P., Hunt, D. C., Kuo, Y.H., Liu, H., Manning, K., McCormick, C., Meehan, T. K., Randel, W. J., Rocken, C., Schreiner, W. S., Sokolovskiy, S. V., Syndergaard, S., Thompson, D. C., Trenberth, K. E., Wee, T.K., Yen, N. L., and Zeng, Z.: The COSMIC/FORMOSAT-3 mission: Early results, B. A,. Meteorol. Soc., 89, 313-333, doi:10.1175/BAMS-89-3-313, 2008.

Beyerle, G., Gorbunov, M. E., and Ao, C. O.: Simulation studies of GPS radio occultation measurements, Radio Sci., 38, 1084, doi:10.1029/2002RS002800, 2003.

Christy, J. R. and Spencer, R. W.: Correcting temperature data sets, Science, 310, 972-973, 2005.

Foelsche, U., Kirchengast, G., and Steiner, A. K.: Global climate monitoring based on CHAMP/GPS radio occultation data, in: First CHAMP Mission Results for Gravity, Magnetic and Atmospheric Studies, edited by: Reigber, C., Lühr, H., and Schwintzer, P., Springer, 397-407, 2003.

Foelsche, U., Borsche, M., Steiner, A. K., Gobiet, A., Pirscher, B., Kirchengast, G., Wickert, J., and Schmidt, T.: Observing upper troposphere-lower stratosphere climate with radio occultation data from the CHAMP satellite, Clim. Dynam., 31, 49-65, doi:10.1007/s00382-007-0337-7, 2008.

Foelsche, U., Pirscher, B., Borsche, M., Kirchengast, G., and Wickert, J.: Assessing the climate monitoring utility of radio occultation data: from CHAMP to FORMOSAT3/COSMIC, Terr. Atmos. Ocean. Sci., 20, 155-170, doi:10.3319/TAO.2008.01.14.01(F3C), 2009a.

Foelsche, U., Pirscher, B., Borsche, M., Steiner, A. K., Kirchengast, G., and Rocken, C.: Climatologies based on radio occultation data from CHAMP and Formosat-3/COSMIC, in: New Horizons in Occultation Research: Studies in Atmosphere and Climate, edited by: Steiner, A. K., Pirscher, B., Foelsche, U., and Kirchengast, G., Springer, Berlin-Heidelberg, doi:10.1007/9783-642-00321-9_15, 181-194, 2009b.

Foelsche, U., Scherllin-Pirscher, B., Ladstädter, F., Steiner, A. K., and Kirchengast, G.: Refractivity and temperature climate records from multiple radio occultation satellites consistent within $0.05 \%$, Atmos. Meas. Tech. Discuss., 4, 1593-1615, doi:10.5194/amtd-4-1593-2011, 2011a.

Foelsche, U., Syndergaard, S., Fritzer, J., and Kirchengast, G.: Errors in GNSS radio occultation data: relevance of the measurement geometry and obliquity of profiles, Atmos. Meas. Tech., 4, 189-199, doi:10.5194/amt-4-189-2011, 2011b.

Gobiet, A. and Kirchengast, G.: Advancements of Global Navigation Satellite System radio occultation retrieval in the upper stratosphere for optimal climate monitoring utility, J. Geophys. Res., 109, D24110, doi:10.1029/2004JD005117, 2004.
Gobiet, A., Kirchengast, G., Manney, G. L., Borsche, M., Retscher, C., and Stiller, G.: Retrieval of temperature profiles from CHAMP for climate monitoring: intercomparison with Envisat MIPAS and GOMOS and different atmospheric analyses, Atmos. Chem. Phys., 7, 3519-3536, doi:10.5194/acp-7-35192007, 2007.

Haimberger, L., Tavolato, C., and Sperka, S.: Toward elimination of the warm bias in historic radiosonde temperature records - some new results from a comprehensive intercomparison of upper-air data, J. Climate, 21, 4587-4606, doi:10.1175/2008JCLI1929.1, 2008.

Hajj, G. A., Kursinski, E. R., Romans, L. J., Bertiger, W. I., and Leroy, S. S.: A technical description of atmospheric sounding by GPS occultation, J. Atmos. Sol.-Terr. Phy., 64, 451-469, doi:10.1016/S1364-6826(01)00114-6, 2002.

Healy, S. B.: Radio occultation bending angle and impact parameter errors caused by horizontal refractive index gradients in the troposphere: A simulation study, J. Geophys. Res., 106, 1187511889, doi:10.1029/2001JD900050, 2001.

Healy, S. B.: Refractivity coefficients used in the assimilation of GPS radio occultation measurements, J. Geophys. Res., 116, D01106, doi:10.1029/2010JD014013, 2011.

Ho, S.-P., Kirchengast, G., Leroy, S., Wickert, J., Mannucci, A. J., Steiner, A. K., Hunt, D., Schreiner, W., Sokolovskiy, S., Ao, C., Borsche, M., von Engeln, A., Foelsche, U., Heise, S., Iijima, B., Kuo, Y.-H., Kursinski, E. R., Pirscher, B., Ringer, M., Rocken, C., and Schmidt, T.: Estimating the uncertainty of using GPS radio occultation data for climate monitoring: intercomparison of CHAMP refractivity climate records from 2002 to 2006 from different data centers, J. Geophys. Res., 114, D23107, doi:10.1029/2009JD011969, 2009.

Kuo, Y.-H., Wee, T.-K., Sokolovskiy, S., Rocken, C., Schreiner, W., Hunt, D., and Anthes, R. A.: Inversion and error estimation of GPS radio occultation data, J. Meteorol Soc. Jpn., 82, 1B, 507531, 2004.

Kursinski, E. R., Hajj, G. A., Bertiger, W. I., Leroy, S. S., Meehan, T. K., Romans, L. J., Schofield, J. T., McCleese, D. J., Melbourne, W. G., Thornton, C. L., Yunck, T. P., Eyre, J. R., and Nagatani, R. N.: Initial Results of Radio Occultation Observations of Earth's Atmosphere Using the Global Positioning System, Science, 271, 1107-1110, doi:10.1126/science.271.5252.1107, 1996.

Kursinski, E. R., Hajj, G. A., Schofield, J. T., Linfield, R. P., and Hardy, K. R.: Observing Earth's atmosphere with radio occultation measurements using the Global Positioning System, J. Geophys. Res., 102, D19, 23429-23465, 1997.

Lackner, B. C.: Exploring trend indicators of climate change from radio occultation and optimal trend detection, Ph.D. thesis, Wegener Center Verlag Graz, Sci. Rep. 38-2010, 2010.

Lemoine, F. G., Kenyon, S. C., Factor, J. K., Trimmer, R. G., Pavlis, N. K., Chinn, D. S., Cox, C. M., Klosko, S. M., Luthcke, S. B., Torrence, M. H., Wang, Y. M., Williamson, R. G., Pavlis, E. C., Rapp, R. H., and Olson, T. R.: The Development of the Joint NASA GSFC and NIMA Geopotential Model EGM96, Nasa/tp-1998-206861, NASA Goddard Space Flight Center, 1998.

Leroy, S. S.: Measurements of geopotential heights by GPS radio occultation, J. Geophys. Res., 102, 6971-6986, 1997.

Leroy, S. S., Dykema, J. A., and Anderson, J. G.: Climate bench- 
marking using GNSS occultation, in: Atmosphere and Climate: Studies by Occultation Methods, edited by: Foelsche, U., Kirchengast, G., and Steiner, A. K., Springer, 287-302, 2006.

Melbourne, W. G., Davis, E. S., Duncan, C. B., Hajj, G. A., Hardy, K. R., Kursinski, E. R., Meehan, T. K., Young, L. E., and Yunck, T. P.: The application of spaceborne GPS to atmospheric limb sounding and global change monitoring, JPL Publ., Jet Propulsion Laboratory, Pasadena, CA, USA, 94-18, 1994.

NIMA: Department of Defense World Geodetic System 1984: Its definitions and relationships with local geodetic systems, Nima tr8350.2, National Imagery and Mapping Agency, available at: http://earth-info.nga.mil/GandG/publications/tr8350.2/ wgs84fin.pdf (last access: 6 March 2011), 2000.

Pirscher, B.: Multi-satellite climatologies of fundamental atmospheric variables from radio occultation and their validation, Ph.D. thesis, Wegener Center Verlag Graz, Sci. Rep., 33-2010, 2010.

Pirscher, B., Foelsche, U., Lackner, B. C., and Kirchengast, G.: Local time influence in single-satellite radio occultation climatologies from Sun-synchronous and non-Sun-synchronous satellites, J. Geophys. Res., 112, D11119, doi:10.1029/2006JD007934, 2007.

Pirscher, B., Foelsche, U., Borsche, M., Kirchengast, G., and Kuo, Y.-H.: Analysis of migrating diurnal tides detected in FORMOSAT-3/COSMIC temperature data, J. Geophys. Res., 115, D14108, doi:10.1029/2009JD013008, 2010.

Rieder, M. J. and Kirchengast, G.: Error analysis and characterization of atmospheric profiles retrieved from GNSS occultation data, J. Geophys. Res., 106, 31755-31770, 2001.

Ringer, M. A. and Healy, S. B.: Monitoring twenty-first century climate using GPS radio occultation bending angles, Geophys. Res. Lett., 35, L05708, doi:10.1029/2007GL032462, 2008.

Rocken, C., Anthes, R., Exner, M., Hunt, D., Sokolovskiy, S., Ware, R., Gorbunov, M., Schreiner, W., Feng, D., Herman, B., Kuo, Y.-H., and Zuo, X.: Analysis and validation of GPS/MET data in the neutral atmosphere, J. Geophys. Res., 102, 2984929866, 1997.

Rocken, C., Sokolovskiy, S., Schreiner, W., Hunt, D., Ho, S.-P., Kuo, Y.-H., and Foelsche, U.: Climate monitoring with radio occultation data: Systematic error sources, presentation at the GPS RO Climate Applications Workshop, 2008.

Rocken, C., Schreiner, W., Sokolovskiy, S., and Hunt, D.: Ionospheric errors in COSMIC radio occultation data, paper presented at the 89th American Meteorological Society Annual Meeting, 2009.

Rüeger, J. M.: Refractive index formulae for radio waves, JS28 Integration of Techniques and Corrections to Achieve Accurate Engineering, FIG XXII International Congress, 2002.
Scherllin-Pirscher, B., Kirchengast, G., Steiner, A. K., Kuo, Y.-H., and Foelsche, U.: Empirical analysis and modeling of errors of atmospheric profiles from GPS radio occultation, Atmos. Meas. Tech., 4, 1875-1890, doi:10.5194/amt-4-1875-2011, 2011.

Schmidt, T., Wickert, J., and Haser, A.: Variability of the upper troposphere and lower stratosphere observed with GPS radio occultation bending angles and temperatures, Adv. Space Res., 46, 150-161, doi:10.1016/j.asr.2010.01.021, 2010.

Schreiner, W., Rocken, C., Sokolovskiy, S., and Hunt, D.: Quality assessment of COSMIC/FORMOSAT-3 GPS radio occultation data derived from single- and double-difference atmospheric excess phase processing, GPS Solut., 14, 13-22, doi:10.1007/s10291-009-0132-5, 2009.

Smith, E. and Weintraub, S.: The constants in the equation for atmospheric refractive index at radio frequencies, Proceedings of the IRE, 41, 1035-1037, 1953.

Sokolovskiy, S. V.: Modeling and inverting radio occultation signals in the moist troposphere, Radio Sci., 36, 441-458, 2001.

Sokolovskiy, S. V.: Effect of superrefraction on inversions of radio occultation signals in the lower troposphere, Radio Sci., 38, 1058, doi:10.1029/2002RS002728, 2003.

Steiner, A. K. and Kirchengast, G.: Error analysis of GNSS radio occultation data based on ensembles of profiles from end-to-end simulations, J. Geophys. Res., 110, D15307, doi:10.1029/2004JD005251, 2005.

Steiner, A. K., Kirchengast, G., and Ladreiter, H. P.: Inversion, error analysis, and validation of GPS/MET occultation data, Ann. Geophys., 17, 122-138, doi:10.1007/s00585-999-0122-5, 1999.

Steiner, A. K., Löscher, A., and Kirchengast, G.: Error characteristics of refractivity profiles retrieved from CHAMP radio occultation data, in: Atmosphere and Climate: Studies by Occultation Methods, edited by: Foelsche, U., Kirchengast, G., and Steiner, A. K., Springer-Verlag, 27-36, 2006.

Steiner, A. K., Kirchengast, G., Lackner, B. C., Pirscher, B., Borsche, M., and Foelsche, U.: Atmospheric temperature change detection with GPS radio occultation 1995 to 2008, Geophys. Res. Lett., 36, L18702, doi:10.1029/2009GL039777, 2009.

Vorob'ev, V. V. and Krasil'nikova, T. G.: Estimation of the accuracy of the atmospheric refractive index recovery from Doppler shift measurements at frequencies used in the NAVSTAR system, Izv. Atmos. Ocean. Phy.+, 29, 602-609, 1994.

Wickert, J., Reigber, C., Beyerle, G., König, R., Marquardt, C., Schmidt, T., Gunwaldt, L., Galas, R., Meehan, T., Melbourne, W., and Hocke, K.: Atmosphere sounding by GPS radio occultation: First results from CHAMP, Geophys. Res. Lett., 28, 3263-3266, 2001. 